This document is the accepted manuscript version of the following article:

Boleti, E., Hueglin, C. , \& Takahama, S. (2019). Trends of surface maximum ozone concentrations in switzerland based on meteorological adjustment for the period 1990-2014. Atmospheric Environment, 213, 326-336.

https://doi .org/10.1016/j.atmosenv.2019.05.018

This manuscript version is made available under the CC-BY-NC-ND 4.0 license http://creativecormons.org/licenses/by-nc-nd/4.0/

\title{
Trends of surface maximum ozone concentrations in Switzerland based on meteorological adjustment for the period 1990-2014
}

\author{
Eirini Boleti ${ }^{\mathrm{a}, \mathrm{b}}$, Christoph Hueglin ${ }^{\mathrm{a}, *}$, Satoshi Takahama ${ }^{\mathrm{b}}$ \\ ${ }^{a}$ Empa, Swiss Federal Laboratories for Materials Science and Technology, Überlandstrasse \\ 129, Dübendorf, Switzerland \\ ${ }^{b}$ EPFL, École Polytechnique Fédérale de Lausanne, Route Cantonale, 1015 Lausanne, \\ Switzerland
}

\begin{abstract}
We investigate the temporal trends of peak ozone in Switzerland for the 1990-2014 time period. The meteorological conditions have a large influence on ozone formation and drive a large part of the variability in ozone observations. Therefore, the influence of meteorology on ozone was estimated using generalized additive models and removed from the ozone observations. A variable selection method was used for model building allowing the detection of the meteorological variables that have the largest effect on the variability of daily maximum ozone at each considered station. It was found that peak concentrations of ozone have been reducing in most of the stations, indicating a positive effect of implemented air pollution control measures on locally produced ozone. In the remote, high alpine site of Jungfraujoch a small upward trend of peak ozone was observed, most likely due to influence of hemispheric background ozone. In the most polluted traffic sites, peak ozone has for a different reason also been increasing until around 2003, when this trend started to level off. In traffic sites the increasing ozone concentrations due to reduced titration by nitrogen monoxide was the dominating process. One of the advantages of meteorological correction of ozone observations for trend estimation is that the uncertainty in
\end{abstract}

\footnotetext{
* Corresponding author

Email address: Christoph.Hueglin@empa.ch (Christoph Hueglin)
} 
the calculated trends is reduced. In addition, trend estimation based on meteorologically corrected ozone is less influenced by exceptional meteorological events during a specific time period, such as heat waves or by temporal changes in meteorological variables.

Keywords: ozone, peak concentrations, trend analysis, variable selection, meteorological adjustment

\section{Introduction}

Ozone $\left(\mathrm{O}_{3}\right)$ is formed in the troposphere by photochemical reactions involving nitrogen oxides $\left(\mathrm{NO}_{x}=\mathrm{NO}_{2}+\mathrm{NO}\right)$, carbon monoxide $(\mathrm{CO})$ and volatile organic compounds (VOCs). High $\mathrm{O}_{3}$ concentrations, as expressed e.g. by the

5 World Health Organization guideline value $\left(100 \mu \mathrm{g} \cdot \mathrm{m}^{-3}\right.$ for the 8 hour running mean) or the European air quality standard $\left(120 \mu \mathrm{g} \cdot \mathrm{m}^{-3}\right.$ for the maximum daily 8 hour running mean), can have severe impacts on human health and ecosystems (World Health Organization, 2006, EEA, 2015). In large parts of Europe, including Switzerland, exceedances occur regularly during warm months of the year, when the combination of favorable weather conditions and availability of precursors lead to increased $\mathrm{O}_{3}$ formation (e.g. Querol et al., 2016). According to Staehelin et al. (1994), concentrations of $\mathrm{O}_{3}$ at remote, rural regions in Europe have almost doubled between 1950s and 1990s due to increasing emissions of the $\mathrm{O}_{3}$ precursors $\mathrm{NO}_{x}$ and VOCs. Since the beginning of 1990s emissions of $\mathrm{NO}_{x}$ and VOCs have been declining in Europe due to implementation of fumission control measures (Colette et al., 2011; Guerreiro et al., 2014; Henschel et al. 2015), such as the use of catalytic converters in the petrol vehicles. The EMEP (Cooperative Programme for Monitoring and Evaluation of the Longrange Transmission of Air Pollutants in Europe) emission inventory reports that ${ }_{20} \mathrm{NO}_{x}$ and non-methane VOC (NMVOC) emissions clearly decreased in Europe between 1990 and 2012 (EEA, 2018), while for Switzerland alone the reported relative reductions are $39 \%$ and $49 \%$ respectively (BAFU, 2016). As a consequence downward trends of maximum concentrations of $\mathrm{O}_{3}$ were observed across 
Europe (EEA, 2009, Yan et al., 2018, Fleming et al., 2018).

Meteorological conditions, such as high air temperature and intense solar radiation or increased wind velocity, strongly influence $\mathrm{O}_{3}$ concentrations at the \urface, as reported in the literature (EEA, 2009, Ordóñez et al. 2005, Pearce et al. 2011). For instance, temperature appears to be a key parameter for $\mathrm{O}_{3}$ in central Europe, especially during high $\mathrm{O}_{3}$ events, while other important meteorological variables are humidity and solar radiation (Otero et al., 2016). Thermal decomposition of peroxyacyl nitrates (PANs) at high temperature conditions lead to higher rates of $\mathrm{O}_{3}$ production (Sillman and Samson, 1995; Vogel et al., 1999, Bärtsch-Ritter et al., 2004). Moreover, increased humidity levels in the atmosphere enhance production of hydroxyl radicals $(\mathrm{OH})$ yielding higher

$35 \mathrm{O}_{3}$ concentrations in the high- $\mathrm{NO}_{x}$ regime (Vogel et al., 1999).

In this study the temporal evolution of peak $\mathrm{O}_{3}$ mixing ratios in Switzerland during 1990-2014, with and without adjustment of meteorological influence, is presented. This complements a trend analysis of mean concentrations of $\mathrm{O}_{3}$ in Switzerland (Boleti et al., 2018), where a method based on de-seasonalization of daily mean $\mathrm{O}_{3}$ has been applied. For the current study, a different approach was used because peak $\mathrm{O}_{3}$ concentrations are typically expressed by temporally localized events and, therefore, de-seasonalization is not meaningful. Our work builds on the work by Ordóñez et al. (2005), however, in our study the effect of meteorology on peak $\mathrm{O}_{3}$ concentrations was investigated by a different statistical

45 approach and by application of a more refined variable selection procedure.

\section{Data}

$\mathrm{O}_{3}$ and $\mathrm{NO}_{x}$ concentration measurements from 21 stations in Switzerland were provided by federal and cantonal authorities in hourly resolution for the time period between 1990 and 2014 (Table1). Note that for 16 of the 21 sites the $\mathrm{O}_{3}$ and $\mathrm{NO}_{x}$ data can also be sourced from AirBase, the air quality database of the European Environmental Agency. The stations included in this study cover regions north and south of the Alps and urban, suburban, rural, elevated and 
remote high alpine site types, they are grouped into five main categories Boleti et al., 2018). The five groups are based on the mean $\mathrm{NO}_{x}$ mixing ratio over the studied period, indicating the proximity of the sites to emission sources of $\mathrm{O}_{3}$ precursors. The categories are the following: (A) the remote, high alpine site in Jungfraujoch not influenced by local sources $\left(\mathrm{NO}_{x} \leq 1 \mathrm{ppb}\right)$, (B) are the alpine and pre-alpine environments with very low local pollution $\left(1<\mathrm{NO}_{x}\right.$ $\leq 10 \mathrm{ppb})$, (C) the rural sites located at low altitudes $\left(10<\mathrm{NO}_{x} \leq 20 \mathrm{ppb}\right)$,

${ }_{60}$ (D) the suburban and urban sites with moderate local pollution $\left(20<\mathrm{NO}_{x} \leq\right.$ $40 \mathrm{ppb}$ ) and (E) comprising all traffic sites which are highly influenced by local emissions $\left(\mathrm{NO}_{x} \geq 40 \mathrm{ppb}\right)$. Due to special characteristics of the sites in Bern and Lausanne (urban sites with the strongest impact of road traffic), these sites were treated as a special category indicated as E2, while the other sites in this group are indicated as E1.

Percentages of missing values vary between $0.32-4.27 \%$ and number of successive missing values in the data are between 4-16 days (except for Tänikon and Grenchen 40 days, Jungfraujoch 43 days and Thônex-Foron 92 days).

The following metrics representing peak or excess $\mathrm{O}_{3}$ concentrations were considered.

1. MTDM: the mean of the ten highest daily maximum $\mathrm{O}_{3}$ concentrations between May and September based on hourly mean data. The same metric has also been calculated for the cold season of the year (October to April).

2. 4-MDA8: the mean of the four highest concentrations of the MDA8 (daily maximum of the 8-hour running mean of hourly $\mathrm{O}_{3}$ concentrations) per year.

3. A-MDA8: the annual maximum MDA8.

4. 90-PERC: the 90th percentile of daily maximum $\mathrm{O}_{3}$.

5. SOMO35: the cumulative excess $\mathrm{O}_{3}$ as calculated from MDA8 exceeding 35 ppb over one year (expressed in ppb.days) (WHO, 2008). The SOMO35 metric can be used for assessment of health impacts.

6. AOT40: it represents the accumulation of $\mathrm{O}_{3}$ over $40 \mathrm{ppb}$ between $8 \mathrm{am}$ 

ergy $\left(\mathrm{CAPE}, \mathrm{J} \cdot \mathrm{kg}^{-1}\right)$, daily maximum sensible surface heat flux $\left(\mathrm{W} \cdot \mathrm{m}^{-2}\right)$, daily/morning/afternoon mean total cloud cover, daily/afternoon mean eastwest/north-south surface stress $\left(\mathrm{N} \cdot \mathrm{s} \cdot \mathrm{m}^{2}\right)$. Additionally, information for the synoptic situation was used, provided as weather type classifications (WTCs, 110 Weusthoff, 2011) from MeteoSwiss, which describe recurrent dynamical patterns. The classification includes 9 categories, namely northeast/indifferent, west-southwest/cyclonic/flat pressure, westerly flow over Northern Europe, east/indifferent, 
high pressure over the Alps, north/cyclonic, west-southwest/cyclonic, high pressure over Central Europe, westerly flow over Southern Europe/cyclonic.

$$
O_{3}(t)=\alpha+\sum_{i=1}^{n} s_{i}\left(M_{i}(t)\right)+\sum_{j=1}^{m}\left(\sum_{k=1}^{p} b_{j k}\left(B_{j k}(t)\right)\right)+s_{0}(t)+\epsilon(t)
$$

where $O_{3}(t)$ denotes the $\mathrm{O}_{3}$ observations (daily maximum and MDA8), $\alpha$ is the intercept, $s_{i}$ are smooth functions (thin plates splines) of the numeric meteorological variables $M_{i}$ and $n$ is the number of the continuous meteorological variables in the model. $B_{j k}$ denote categorical variables where $j$ is the variable, 135 categorical variables in the model and $p$ the number of categories. The temporal trend is modeled by the smooth function $s_{0}, t$ denotes the time variable 
Table 1: Table with the studied stations in Switzerland, ranked by increasing mean $\mathrm{NO}_{x}$ concentration from top to bottom. Stations are categorized according to mean $\mathrm{NO}_{x}$ value during the studied period, where $\mathrm{A}: \mathrm{NO}_{x} \leq 1 \mathrm{ppb}$, B: $1<\mathrm{NO}_{x} \leq 10 \mathrm{ppb}$, C: $10<\mathrm{NO}_{x}$ $\leq 20 \mathrm{ppb}, \mathrm{D}: 20<\mathrm{NO}_{x} \leq 40 \mathrm{ppb}$, and $\mathrm{E}: \mathrm{NO}_{x} \geq 40 \mathrm{ppb}$. Category $\mathrm{E} 2$ indicates sites in urban environment with high traffic activity throughout the day. (Cat. indicates the station's category.)

\begin{tabular}{|c|c|c|c|c|c|}
\hline Station & Code & Type & $\mathbf{N O}_{x}(\mathbf{p p b})$ & Time period & Cat. \\
\hline Jungfraujoch & JUN & Remote, High Alpine (3578 m a.s.l.) & 0.3 & $1990-2014$ & A \\
\hline Davos & DAV & Rural, Elevated (<1000 m a.s.l.) & 2.9 & $1991-2014$ & $\mathrm{~B}$ \\
\hline Chaumont & CHA & Rural, Elevated (<1000 m a.s.l.) & 4.2 & $1990-2014$ & $\mathrm{~B}$ \\
\hline Rigi & $\mathrm{RIG}$ & Rural, Elevated (<1000 m a.s.l.) & 4.7 & $1991-2014$ & $\mathrm{~B}$ \\
\hline Tänikon & TAE & Rural & 11.4 & $1990-2014$ & $\mathrm{C}$ \\
\hline Payerne & PAY & Rural & 11.6 & $1990-2014$ & $\mathrm{C}$ \\
\hline Grenchen-Zentrum & GRE & Urban & 21.0 & $1990-2014$ & $\mathrm{D}$ \\
\hline Basel-Binningen & BAS & Suburban & 22.3 & $1990-2014$ & $\mathrm{D}$ \\
\hline Frauenfeld-Bahnhofstrasse & FRA & Suburban & 26.1 & $1995-2014$ & $\mathrm{D}$ \\
\hline Magadino & $\mathrm{MAG}$ & Rural & 26.2 & $1991-2014$ & $\mathrm{D}$ \\
\hline Thônex-Foron & FOR & Suburban & 30.8 & $1990-2014$ & $\mathrm{D}$ \\
\hline Dübendorf & DUE & Suburban & 31.5 & $1991-2014$ & $\mathrm{D}$ \\
\hline Liestal-LHA & LIE & Suburban, Traffic & 32.3 & $1990-2014$ & $\mathrm{D}$ \\
\hline Zürich-Alte Kaserne & ZUE & Urban & 33.3 & $1991-2014$ & $\mathrm{D}$ \\
\hline Basel-St.Johann & BSJ & Urban & 34.6 & $1990-2014$ & $\mathrm{D}$ \\
\hline Lugano & $\mathrm{LUG}$ & Urban & 35.5 & $1990-2014$ & $\mathrm{D}$ \\
\hline Zürich-Stampfenbachstrasse & $\mathrm{ZSS}$ & Urban, Traffic & 42.7 & $1995-2014$ & $\mathrm{E} 1$ \\
\hline Sion & $\mathrm{SIO}$ & Rural, Highway & 45.5 & $1990-2014$ & $\mathrm{E} 1$ \\
\hline Lausanne & $\mathrm{LAU}$ & Urban, Traffic & 53.9 & 1991-2014 & $\mathrm{E} 2$ \\
\hline Härkingen & $\mathrm{HAE}$ & Rural, Highway & 68.0 & $1993-2014$ & E1 \\
\hline Bern & BER & Urban, Traffic & 82.0 & $1991-2014$ & $\mathrm{E} 2$ \\
\hline
\end{tabular}


expressed as the Julian day (number of days since January 1, 4713 BCE at noon UTC). $\epsilon$ stands for the residuals of the model. In our models the WTCs and the day of the week are included as categorical variables. The GAMs were calculated using the $m g c v$ library in $\mathrm{R}$ ( $\mathrm{R}$ Development Core Team, 2017).

\subsection{Selection of meteorological variables}

GAMs were constructed for two seasons (May-September and OctoberApril) for the daily maximum and MDA8 $\mathrm{O}_{3}$, resulting in four models per site. A selection method was applied for each of the models, to identify the most important meteorological variables for explaining $\mathrm{O}_{3}$ variability. Amongst all available predictors, the ones that best define the model were selected based on the Akaike information criterion (AIC).

$$
A I C=-2 \cdot \log (L)+k \cdot n
$$

where $L$ is the maximum value of the likelihood function for the model, $k$ the values used for VIF and AIC. The maximum VIF used here is 2.5, which corresponds to an accepted maximum $R^{2}=0.6$ between two numerical explanatory variables. A large penalty parameter $k$ means strong penalization of models 
is usually used in the literature (e.g. Barmpadimos et al., 2011), while $k>20$ (e.g. $k=24$ ) leads to models with very small number of explanatory variables and relatively low explained variability $\left(R^{2}\right)$. Eventually, for the AIC penalty parameter the most appropriate value was found to be $k=20$.

The variable selection method works as follows (Barmpadimos et al., 2011 Jackson et al. 2009). (i) The first variable is selected, by constructing GAMs using each one of the available explanatory variables every time. The GAM with the variable that results in the lowest AIC is selected. (ii) The next variable is selected by adding the rest of the explanatory variables one by one in the 175 GAM that was selected in step (i). Again, the GAM with the lowest AIC is selected. (iii) The variable that was chosen in step (i) is removed and each one of the remaining variables is added to the model. If this process results in a model with lower AIC than the model selected in step (ii), then the model from the current step is chosen. (iv) Collinearity is tested, by calculating the been selected before. If it exceeds 2.5 then the new variable is removed from the model. (v) Steps (ii) to (iv) are repeated until no further reduction of the AIC can be achieved.

\subsection{Meteorological adjustment}

The meteorological adjustment was performed after identifying the best models for each station. Meteo-adjusted daily maximum and MDA8 $\mathrm{O}_{3}$ time series were calculated as

$$
O_{3} a d j(t)=\alpha+s_{0}(t)+\epsilon(t)
$$

Meteorologically adjusted $\mathrm{O}_{3}$ can be interpreted as the concentration of $\mathrm{O}_{3}$ that would prevail on the considered day at average conditions as represented by the selected meteorological variables. For MTDM and 4-MDA8, the days of the ten highest daily maximum concentrations and of the four highest MDA 8 of each year were identified from the corresponding observations. The meteo-adjusted 
MTDM and 4-MDA8 were calculated from $\mathrm{O}_{3} a d j(t)$ for the same days that were previously identified. The meteo-adjusted 90-PERC values were calculated from the $\mathrm{O}_{3} a d j(t)$. Eventually, meteo-adjusted trends were calculated using the Theil-Sen trend estimator and a linear regression model as explained in section 3.1. Meteo-adjustment was not applied for SOMO35 and AOT40, because the cumulative sum of meteorologically adjusted $\mathrm{O}_{3}$ above a certain threshold can hardly be interpreted and does no more represent a meaningful metric for annual or seasonal exposure to excess $\mathrm{O}_{3}$.

\section{Results}

\subsection{Meteorological influence on maximum $\mathrm{O}_{3}$ concentrations}

The most often selected variables in the GAMs for the daily maximum and MDA8 $\mathrm{O}_{3}$ during warm months are the daily maximum temperature, daily mean humidity, morning mean CAPE, north-south surface stress (either daily mean or afternoon mean) and east-west surface stress (either daily mean or afternoon mean) (Table. 2). Similar to Ordóñez et al. (2005), daily maximum temperature was found to be the most important variable in nearly all stations. The non-linear effect of temperature on $\mathrm{O}_{3}$ as described by the GAM models is exemplified in Fig. 1 for the suburban site in Dübendorf, a moderately polluted site with little emissions of ozone precursors in the immediate vicinity. Temperature can be regarded as a proxy for conditions favoring ozone formation. An important reason for this strong relationship between $\mathrm{O}_{3}$ and temperature is that high temperature is associated with high solar radiation. Solar radiation increases photolysis rates of $\mathrm{NO}_{2}$, which leads to increased $\mathrm{O}_{3}$ production. In addition, emissions of precursors like biogenic VOCs increase with temperature (Coates et al. 2016). Also, reaction rates such as thermal decomposition of PAN is enhanced at high temperature, which intensifies $\mathrm{O}_{3}$ formation (Sillman et al. 1990). The effect of temperature on $\mathrm{O}_{3}$ is also illustrated in Fig. 2 where daily

220 maximum $\mathrm{O}_{3}$ as observed at all the considered sites is grouped into five year time periods and shown for $10^{\circ} \mathrm{C}$ temperature bins. It seems that for tempera- 
tures above $20^{\circ} \mathrm{C}$ the sensitivity of daily maximum $\mathrm{O}_{3}$ on ambient temperature is decreasing with time, an effect that has also been observed for the U.S. by Bloomer et al. (2009). A smaller rate of increase of $\mathrm{O}_{3}$ with temperature can 225 be expected when ambient $\mathrm{NO}_{x}$ concentrations are decreasing (Coates et al. 2016). The changing sensitivity of ozone on temperature leads to the risk that GAMs specified for the whole time period might underestimate (overestimate) the effect of temperature on $\mathrm{O}_{3}$ in the first (last) years of the time series. Consequently, this results in too strong downward trends in meteo-adjusted peak $\mathrm{O}_{3}$. The impact of the changing sensitivity of temperature on ozone has been tested and was found to be negligible (see supplementary material, section S7).

Daily maximum $\mathrm{O}_{3}$ is on average decreasing with increasing mean relative humidity as shown in Fig. 1 for the suburban site in Dübendorf, most probably linked to increased cloudiness conditions. The opposite effect is usually ditions enhance production of $\mathrm{OH}$, and thus lead to higher $\mathrm{O}_{3}$ production (Vogel et al. 1999, Seinfeld and Pandis, 2016). Increasing CAPE could in principle lead to higher or lower concentration of $\mathrm{O}_{3}$, depending on the vertical gradient of $\mathrm{O}_{3}$ as well as on the $\mathrm{O}_{3}$ formation rate in the boundary layer. We find 240 $\mathrm{O}_{3}$ concentrations are typically higher at high instability of the troposphere and strong vertical mixing as associated with high CAPE values (Davies et al., 2013). North-south/east-west surface stress are explanatory variables representing the prevailing wind conditions, i.e. increasing positive values mean increasing northsouth/east-west wind velocity and increasing negative values indicate increasing wind velocities in the opposite direction. Strong wind leads to lower $\mathrm{O}_{3}$ mixing ratios in most stations, as shown for Dübendorf in Fig. 1. Nevertheless, the effect of wind direction on $\mathrm{O}_{3}$ depends on specific local conditions and can vary among the studied sites. In agreement with Ordóñez et al. (2005), the day of week has not been selected as an important explanatory variable in the GAM models for the summer months. The day of week was, however, selected in the GAM models for the cold season. Brönnimann and Neu (1997) found on 
Table 2: Table with the most often selected meteorological variables and the number of sites in which they were selected for the GAMs for the warm period May-September (in total 18 sites, where the selection was applied).

\begin{tabular}{|c|c|c|}
\hline Meteorological variable & $\begin{array}{l}\text { number of sites } \\
\text { daily maximum } \mathrm{O}_{3}\end{array}$ & $\begin{array}{l}\text { number of sites } \\
\text { MDA } 8 \mathrm{O}_{3}\end{array}$ \\
\hline Temperature - daily maximum & 16 & 15 \\
\hline Humidity - daily mean & 10 & 14 \\
\hline CAPE - morning mean & 5 & 7 \\
\hline East-West Surface stress - daily mean/afternoon mean & 8 & 9 \\
\hline North-South Surface stress - daily mean/afternoon mean & 9 & 9 \\
\hline
\end{tabular}

the one hand that during favourable weather conditions $\mathrm{O}_{3}$ concentrations in Switzerland were lower during weekends than on weekdays. This dependence on the day of week can for daily maximum $\mathrm{O}_{3}$ also directly be seen in our measurements. However, including the day of week in the GAMs did not improve the models with respect to AIC (see also supplementary material). On the other hand, Brönnimann and Neu (1997) found higher $\mathrm{O}_{3}$ concentrations on weekends compared to weekdays for weather conditions that are not favourable for $260 \mathrm{O}_{3}$ formation. The effect that lower $\mathrm{NO}_{x}$ emissions during the weekend can in polluted areas lead to higher $\mathrm{O}_{3}$ production has also been described by Marr and Harley (2002).

The meteorological variables that were selected in our GAM models agree well with the ones selected in the study by Ordóñez et al. (2005). Temperature, humidity and variables representing wind speed were selected in most stations in both studies. However, in contrast to Ordóñez et al. (2005) who found global radiation to be an important variable at many stations, radiation was hardly selected in this study. This difference is explained by the variable selection approach applied in this study that prevents co-selection of variables that are highly correlated such as radiation and temperature or multiple variables characterizing similar phenomena (e.g., WTC and wind conditions).

The meteorologically driven variability of daily maximum and MDA8 $\mathrm{O}_{3}$ explained by the GAMs is expressed by the coefficient of determination $R^{2}$. In 

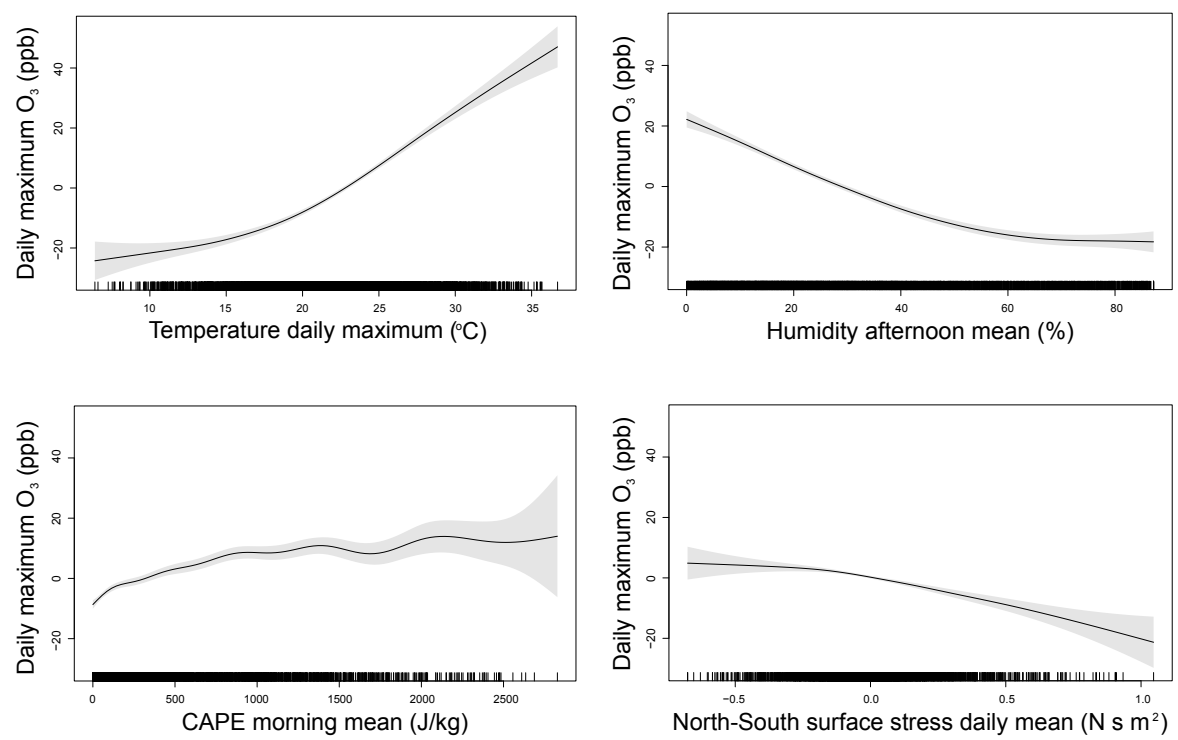

Figure 1: Example of relationship between daily maximum $\mathrm{O}_{3}$ and some of selected meteorological variables for the suburban site Dübendorf.

the present study $R^{2}$ for the daily maximum $\mathrm{O}_{3}$ in the warm season ranges between $52-74 \%$ (except for Jungfraujoch only 24\%) and in the cold season $63-82 \%$ (in Jungfraujoch 48\%), while for the MDA8 $\mathrm{O}_{3}$ in the warm period $R^{2}$ is between 53 and $78 \%$ (in Jungfraujoch 29\%) and in the cold period 50$82 \%$ (in Jungfraujoch 50\%). It should be noted that the applied meteorological adjustment allows the removal of a large fraction but certainly not all of the variability in the $\mathrm{O}_{3}$ data that is caused by meteorology. However, partial removal of meteorology driven variability from the observations is very useful for trend estimation as detailed below. Model assumptions for normally distributed residuals are fulfilled, with models for the warm season performing better than the ones for the cold season with respect to the constant variance assumption (see supplementary material).

The meteorological adjustment leads to a reduced variability in the daily maximum and MDA8 $\mathrm{O}_{3}$ as shown in Fig. 3. Note that MTDM and 4-MDA8 calculated from meteo-adjusted daily maximum and MDA8 $\mathrm{O}_{3}$ are systemati- 


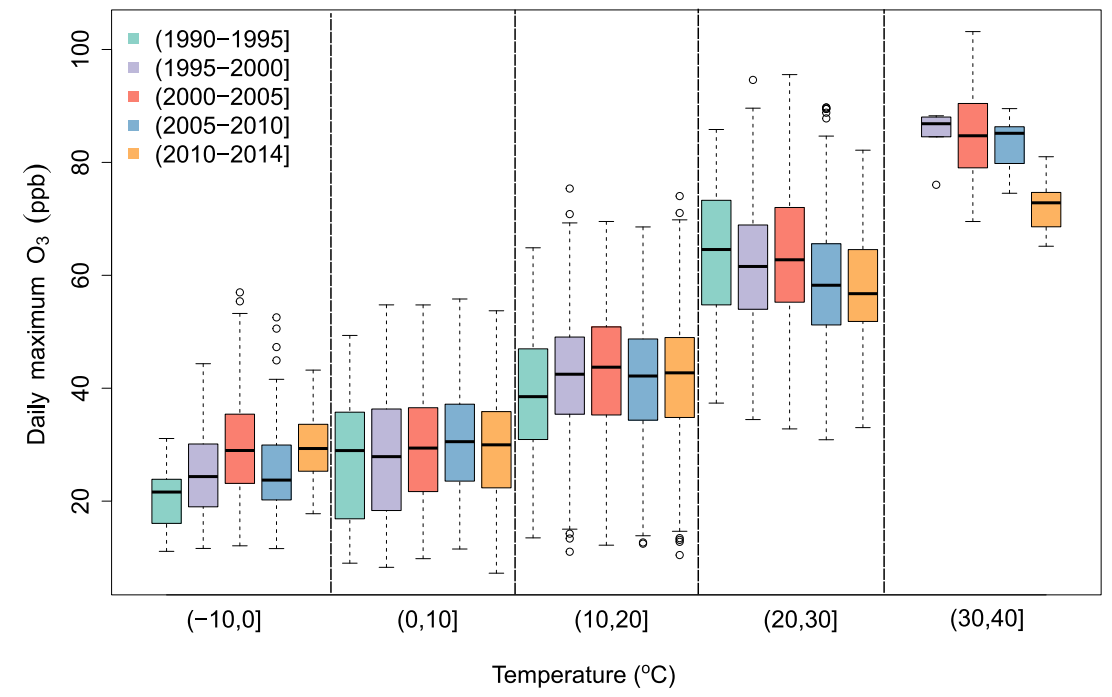

Figure 2: Daily maximum $\mathrm{O}_{3}$ for different daily maximum temperature ranges and time periods averaged for all studied sites. Box encompasses 25 th to 75 th percentile with a line at the median; whiskers extend to 1.5 times the interquartile range. Values for each site category are shown in the supplementary material.

cally lower than when calculated directly from the measured values (Fig. 4), because these metrics exclusively include observations at meteorological conditions that are favorable for $\mathrm{O}_{3}$ formation. The meteo-adjustment leads to a normalization of the measured $\mathrm{O}_{3}$ to concentrations that are more representative for average meteorological conditions.

\subsection{Trends of peak $\mathrm{O}_{3}$ concentrations}

Meteo-adjustment removes meteorologically driven variability from the observations and, therefore, allows trend calculations with smaller uncertainties. Consequently, trend estimations from meteo-adjusted data were more often statistically significant compared to the trends that were directly determined from the measurements (Figs. 5 and 6). Reduced uncertainty is a main advantage of meteo-adjustment as it allows the earlier detection of significant trends in air quality measurements. 

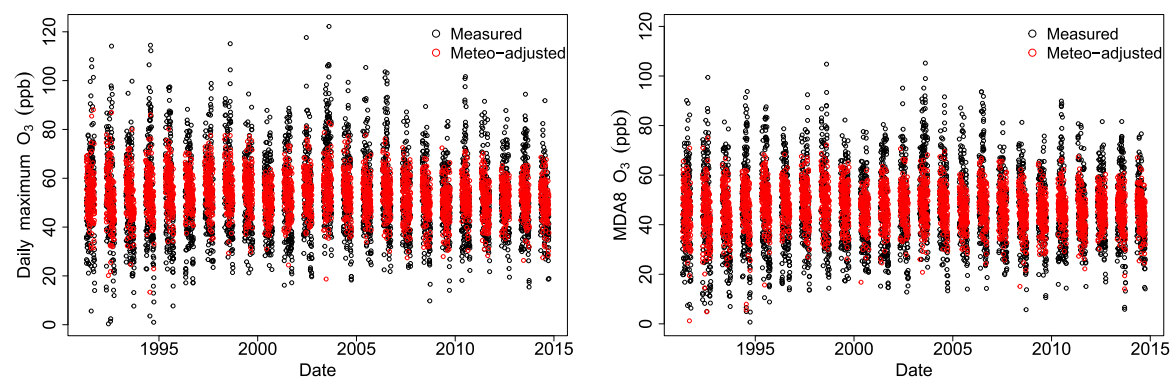

Figure 3: $\quad$ Measured and meteo-adjusted daily maximum $\mathrm{O}_{3}$ (left) and MDA8 $\mathrm{O}_{3}$ (right) time series for the suburban site in Dübendorf.
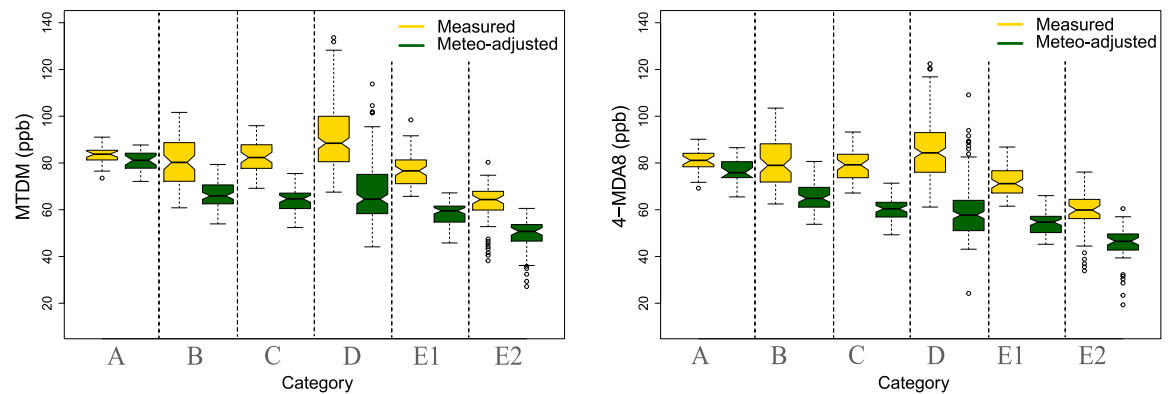

Figure 4: Box-whisker plot for the MTDM and 4-MDA8 mixing ratios as calculated from measured and meteo-adjusted data separated for the different site categories.

The larger negative trends estimated for most stations after meteo-adjustment can be attributed to additional removal of systematic variations in meteorological variables that occur in short-term and long-term time scales. For example, the hot summers of 2003 and 2006 (Ordóñez et al., 2005: Schnell et al., 2014. Carro-Calvo et al. 2017) were exceptionally favorable for $\mathrm{O}_{3}$ formation, leading to less negative trends when calculated directly from the observations (supplementary material, Section S8). As can be seen in Fig. 7. MTDM and 4-MDA8 values corresponding to the years 2003 and 2006 stand out from the other data points. After the removal of the meteorological influence from the observations these points lie very close to the trend line, leading to the estimation of a higher negative trend. Meteo-adjustment also normalizes $\mathrm{O}_{3}$ trends to the average meteorological condition of the study period, removing the effect of 


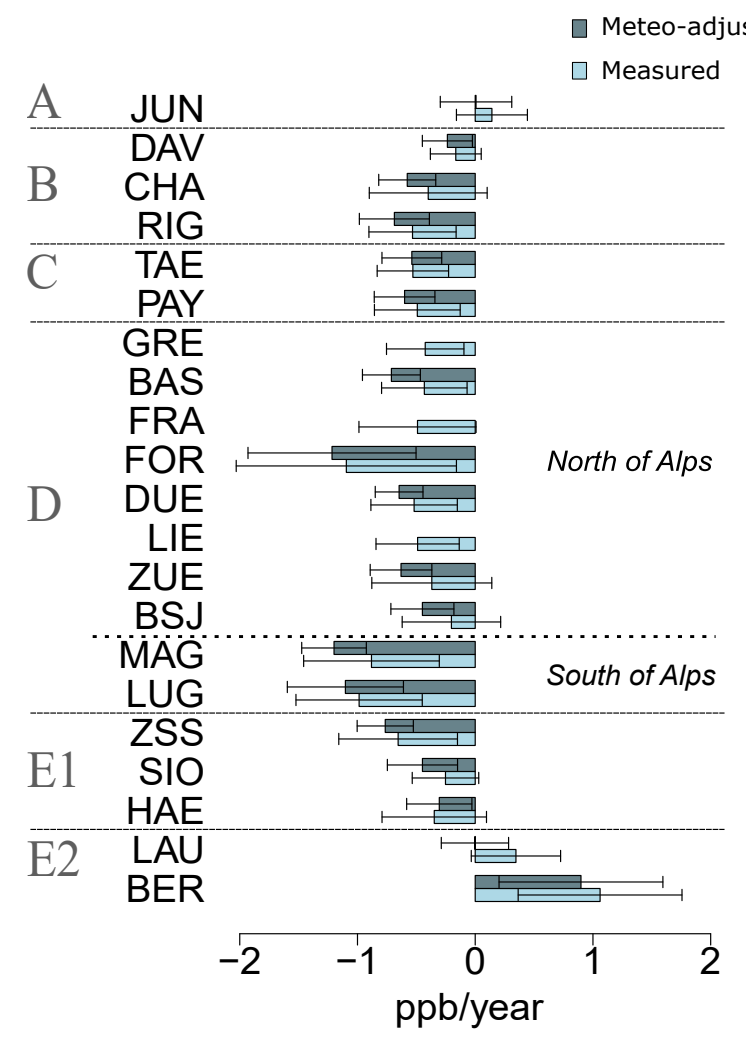

Figure 5: Theil-Sen trends of MTDM for the studied sites across Switzerland. Error bars show the $95 \%$ CI. Note that, for the stations FRA, GRE and LIE, no complete meteorological information was available; therefore, meteo-adjustment was not applied.

the small, long-term increase in temperature observed during the study period (supplementary material, section S8) which otherwise dampens the trend on $\mathrm{O}_{3}$ variation that is not due to meteorological factors.

In general, peak $\mathrm{O}_{3}$ mixing ratios in Switzerland decreased between 1990 and 2014 (Table 3). MTDM and 4-MDA8 showed on average significant decreasing trends during 1990-2014 for the categories with low or moderate $\mathrm{NO}_{x}$ pollution B, C and D and for the highly polluted E1 as well (Figs. 5. 6). For the categories $\mathrm{A}$ and $\mathrm{E} 2$, i.e. remote stations and the most polluted urban traffic sites, increasing trends of MTDM and 4-MDA8 were observed. Peak $\mathrm{O}_{3}$ trends 


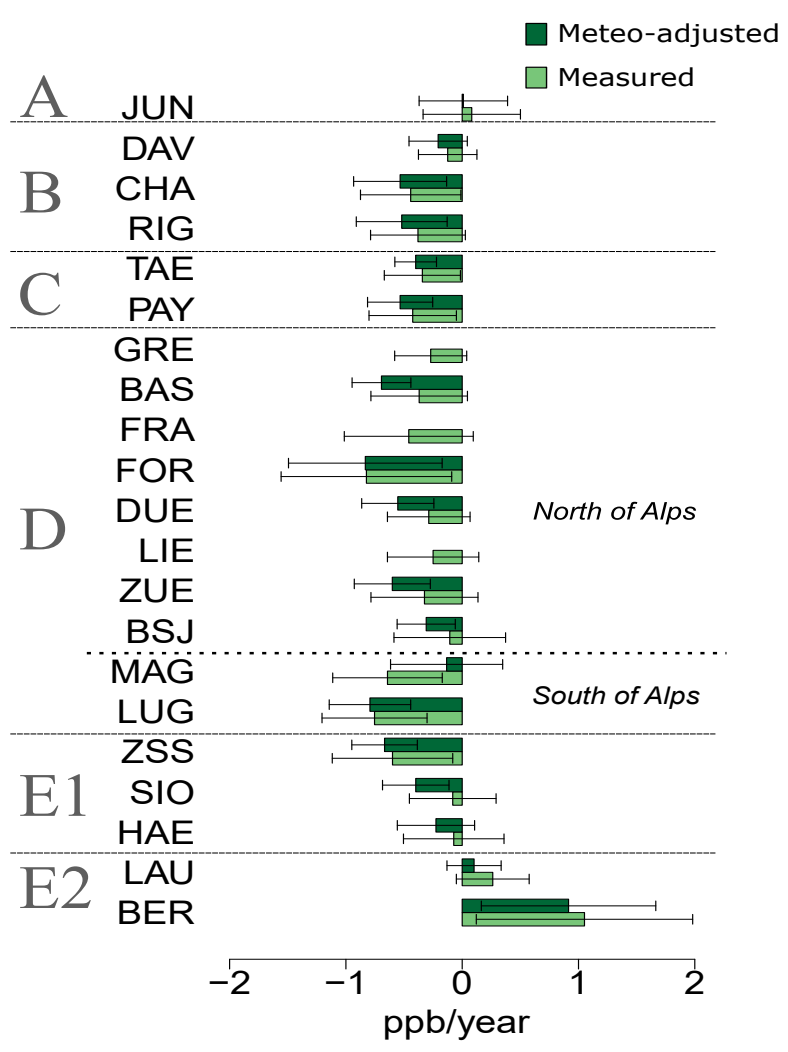

Figure 6: Same as in Fig. 5 for 4-MDA8.

mostly reflect changes in local photochemical production, resulting from changes in $\mathrm{O}_{3}$ precursors concentrations. More precisely, in the studied sites $\mathrm{NO}$ and $\mathrm{NO}_{2}$ mixing ratios have decreased between 1990 and 2014 (Fig. 8). It is clear that at the more remote sites the absolute reduction rate is much smaller than at sites closer to main $\mathrm{NO}_{x}$ sources. At sites close to traffic (categories $\mathrm{E} 1$ and E2) NO had a much higher rate of decrease compared to $\mathrm{NO}_{2}$. This is partly due to the higher fraction of $\mathrm{NO}_{2}$ in the emissions from newer generations of diesel vehicles (Grice et al., 2009; Grange et al., 2017) and partly because most of the $\mathrm{NO}_{x}$ is emitted as $\mathrm{NO}$. A substantial amount of $\mathrm{NO}_{2}$ is instantaneously formed by the reaction of $\mathrm{NO}$ with $\mathrm{O}_{3}$.

The remote site of Jungfraujoch (JUN, $3580 \mathrm{~m}$ a.s.l.) in category A, showed 

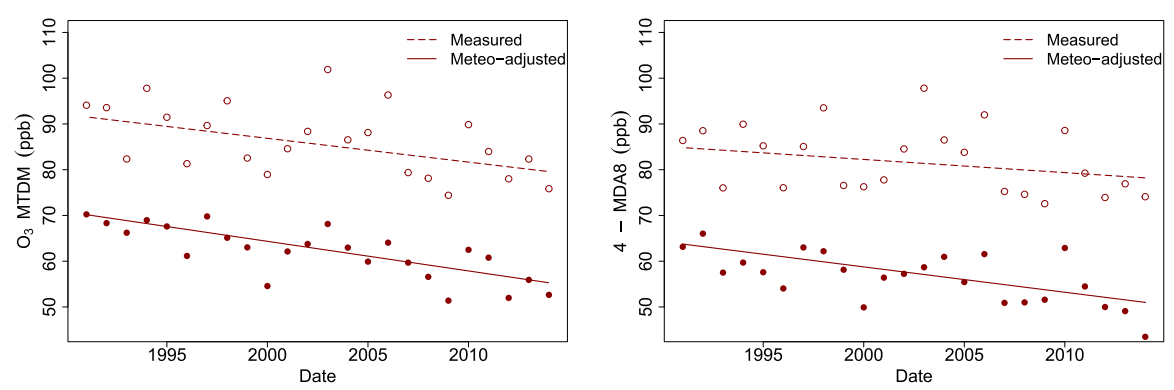

Figure 7: Trends of measured and meteo-adjusted MTDM (left) and 4-MDA8 (right) for the suburban site in Dübendorf.

an increase for MTDM and 4-MDA8 (Figs. 5 and 6). However, it was observed that the increase of the peak $\mathrm{O}_{3}$ metrics is slowing down after beginning of 2000s, likely due to the influence of background $\mathrm{O}_{3}$ concentrations (Derwent et al., 2007, Vingarzan, 2004). Background $\mathrm{O}_{3}$ is attributed to hemispheric transport influenced by emissions in North America and Southeast Asia as [well as transport of $\mathrm{O}_{3}$ from the stratosphere (Derwent et al., 2004; Cooper 340 et al., 2014, Dentener et al., 2010; Hess and Zbinden, 2013). Because locally produced $\mathrm{O}_{3}$ at this station is very low, it is expected that mixing ratios of mean and peak $\mathrm{O}_{3}$ have a similar temporal evolution. For daily mean $\mathrm{O}_{3}$ at Jungfraujoch, an upward trend has been found for the time between 1990 and $2003\left(+0.54 \mathrm{ppb} /\right.$ year). This trend stopped after 2003 and mean $\mathrm{O}_{3}$ started to slightly decline by $-0.17 \mathrm{ppb} /$ year (Boleti et al., 2018). At the remote site Mace Head (Ireland) a similar trend of European background $\mathrm{O}_{3}$ as obtained for Jungfraujoch has been found. According to Derwent et al. (2018) monthly $\mathrm{O}_{3}$ means were increasing since 1987 at a rate of $+0.34 \mathrm{ppb} /$ year and started to decrease after 2007 by $-0.02 \mathrm{ppb} /$ year $^{2}$.

350 In categories $\mathrm{B}, \mathrm{C}, \mathrm{D}$ and $\mathrm{E} 1$ the evolution of peak $\mathrm{O}_{3}$ trends is similar. MTDM and 4-MDA8 decreased in all cases (Figs. 5 and 6). In the environments of categories $\mathrm{B}$ and $\mathrm{C}$, the decrease of $\mathrm{NO}_{x}$ since the 1990s has contributed to the decline of peak $\mathrm{O}_{3}$. In the urban and suburban sites of categories D and E1 the decrease of $\mathrm{NO}_{2}$ and $\mathrm{NO}$ was more pronounced than in rural and remote 


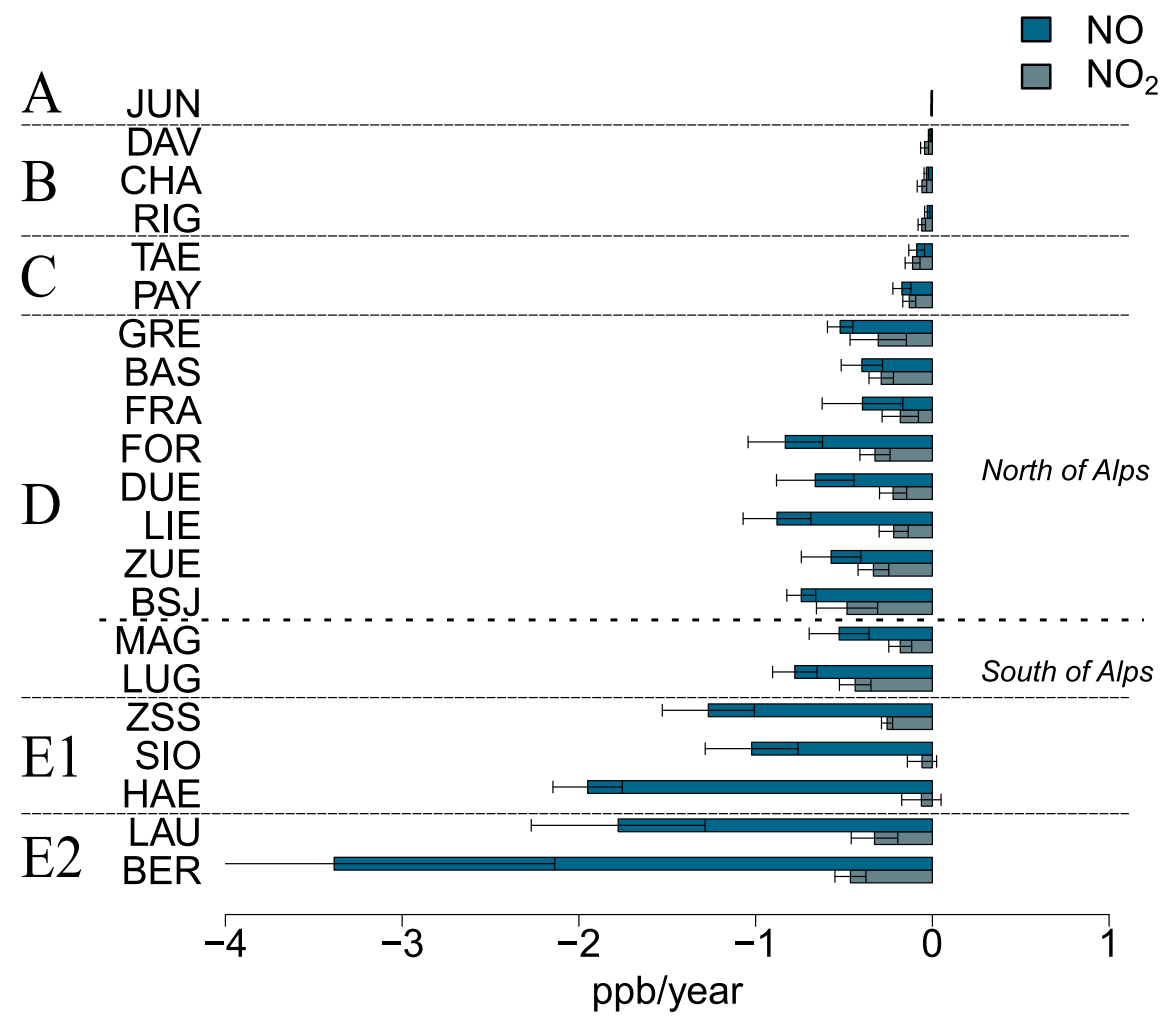

Figure 8: Theil-Sen trends of daily mean $\mathrm{NO}$ and $\mathrm{NO}_{2}$ during 1990-2014 (in ppb/year) for the studied sites in Switzerland based on yearly averages. Error bars show the $95 \%$ CIs obtained by the Theil-Sen trend estimator.

areas (Fig. 8), with the decrease rate being higher before mid-2000s compared to late-2000s (Boleti et al. 2018). A similar trend behavior has been found for total VOCs (not shown).

A few of the urban sites in category E1 show an inflection point in the trend (Fig. 9). For instance in Härkingen (HAE), the trend is mostly flat until 2005 and decreases afterwards, which also leads to the calculation of a smaller negative trend for the whole period 1990-2014. This behavior can qualitatively be understood by $\mathrm{O}_{3}$ isopleths diagrams that describe maximum $\mathrm{O}_{3}$ production in relation to initial $\mathrm{NO}_{x}$ and VOC concentrations (Finlayson-Pitts and Pitts, 
Table 3: Theil-Sen trends (mean value per group) of MTDM, 4-MDA8 and SOMO35. First and second values indicate the measured and meteo-adjusted trend respectively. In category D the mean trends are additionally shown for the sites north and south of the Alps separately. For SOMO35 meteo-adjustment was not applied and a linear trend is not meaningful for categories A and B due an inflection point during the studied time period. Cat. indicates the station's category.

\begin{tabular}{l|l|l|l|l}
\multicolumn{1}{l}{ station's category. } \\
\multicolumn{1}{l|}{ Cat. } & \multicolumn{1}{l}{ Environment } & \multicolumn{1}{l}{$\begin{array}{l}\text { MTDM } \\
\text { (ppb/year) }\end{array}$} & \multicolumn{1}{l}{$\begin{array}{l}\text { 4-MDA8 } \\
\text { (ppb/year) }\end{array}$} & \multicolumn{1}{l}{$\begin{array}{l}\text { SOMO35 } \\
\text { (pp.days/year) }\end{array}$} \\
\hline A & High alpine & $0.14 / 0.01$ & $0.08 / 0.01$ & - \\
B & Alpine \& pre-alpine & $-0.36 /-0.5$ & $-0.31 /-0.42$ & - \\
C & Rural, low altitude & $-0.51 /-0.57$ & $-0.38 /-0.46$ & -16.76 \\
D & Suburban \& urban & $-0.64 /-0.85$ & $-0.47 /-0.55$ & 2.59 \\
\hline \hline$D$ & North of Alps & $-0.52 /-0.73$ & $-0.38 /-0.59$ & 2.37 \\
$D$ & South of Alps & $-0.93 /-1.15$ & $-0.69 /-0.46$ & -8.21 \\
\hline \hline E1 & Traffic sites & $-0.41 /-0.5$ & $-0.25 /-0.43$ & 0.57 \\
E2 & Urban, high traffic & $0.70 / 0.44$ & $0.65 / 0.50$ & 47.22 \\
\hline
\end{tabular}

2000). At locations in the vicinity of emissions sources and high $\mathrm{NO}_{x}$ levels (VOC-limited regime), reduction of $\mathrm{NO}_{x}$ without equivalent reduction of VOCs can lead to increased $\mathrm{O}_{3}$ production, which likely has been the case for sites like HAE during the 1990s and until 2005. After mid-2000s the decrease of $\mathrm{NO}_{x}$ and VOCs levelled off at similar rates (EEA, 2017), leading to the observed downward trends until 2014.

The sites in Magadino (MAG) and Lugano (LUG), both located south of the Alps, experienced a larger decrease compared to the other sites in category D. For instance, the MTDM trend is $-1.15 \mathrm{ppb} /$ year averaged for MAG and LUG only, while for the other sites in category D the determined trend is $0.73 \mathrm{ppb} /$ year (Table 3). Due to their location in the south of the Alps, these two sites have special climatic conditions and are affected by polluted air masses originating in the Milan industrial region (Brönnimann et al. 2002, Prévôt et al. 1997). As was shown with a backward trajectories analysis by Prévôt et al. (1997), $\mathrm{O}_{3}$ precursors are transported from the Milan area towards southern 

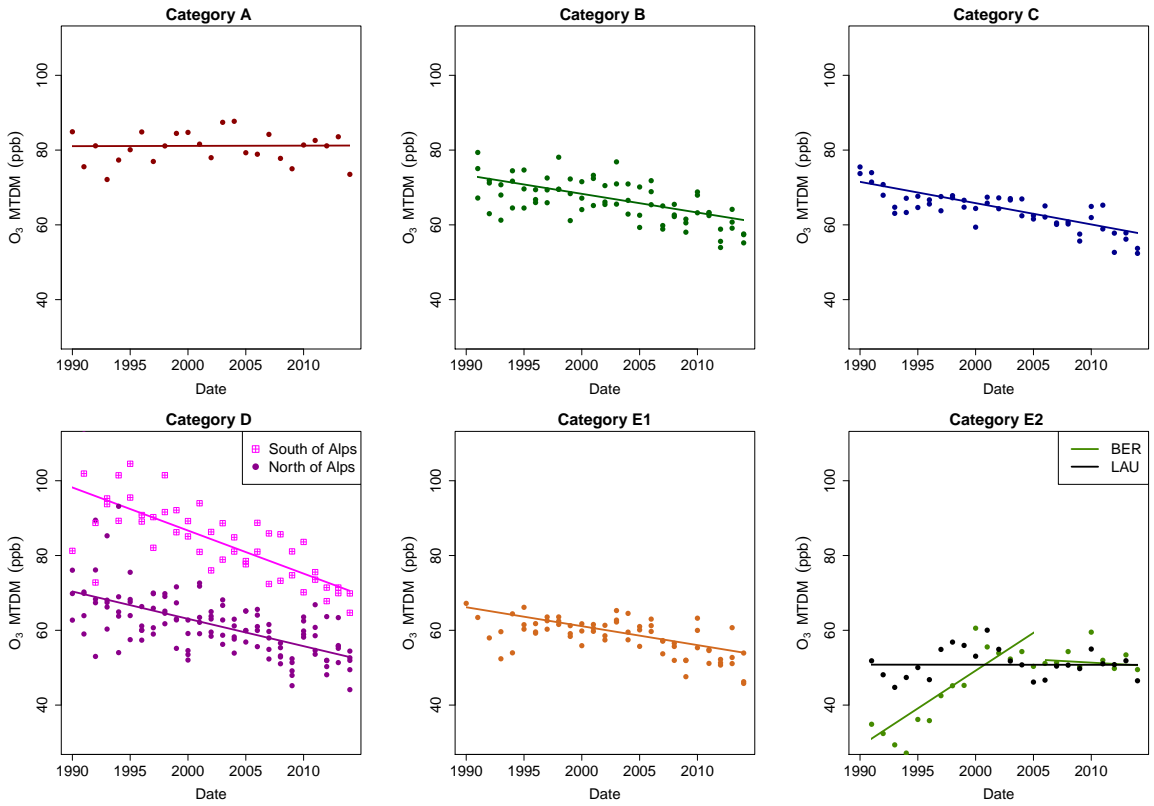

Figure 9: Theil-Sen trend lines are shown as means of all sites in each category for the meteoadjusted MTDM. Points show the yearly average value for all sites in the category. Trend in Bern (BER) is shown additionally for the MTDM in two periods (1990-2004 and 2004-2014), due to exceptional behavior compared to the other studied sites. Sites in category D located south and north of the Alps are indicated with different color and shapes to point out their differences in $\mathrm{O}_{3}$ mixing ratios trends.

Switzerland and blocked by the Alps. Therefore, higher $\mathrm{O}_{3}$ peaks are observed in sites south of the Alps compared to the other sites in category D (Fig. 9 in category D).

Category E2 includes the urban stations in Lausanne (LAU) and Bern (BER), that are located next to urban roads with high traffic. At these locations positive trends for the MTDM and 4-MDA8 were observed, linked to the much stronger decrease of $\mathrm{NO}$ compared to $\mathrm{NO}_{2}$ (Fig. 8). The resulting reduced titration of $\mathrm{O}_{3}$ by $\mathrm{NO}$ partly explains the positive trends at the above sites (Monks, 2000). Especially BER experienced a pronounced increase, although a level off is observed after 2004 (inset of Fig 9). The inflection point in BER can be explained -similar to HAE- by the changing reduction rate of $\mathrm{NO}_{x}$ in the 
not meaningful as the trend behaviour before and after 2004 would be underand overestimated, respectively. Similar to the metrics for peak $\mathrm{O}_{3}$, an upward trend of daily mean de-seasonalized $\mathrm{O}_{3}$ concentrations in LAU and BER has been observed, with sign of stabilization after around 2010 (Boleti et al., 2018). $\mathrm{O}_{3}$ metrics is strongly influenced by the development of the morning $\mathrm{O}_{3}$ baseline determined by the extent of NO titration. Because of the strong reductions in $\mathrm{NO}_{x}$ emissions, less titration of $\mathrm{O}_{3}$ through reaction with $\mathrm{NO}$ led to generally higher $\mathrm{O}_{3}$ levels at these locations (Boleti et al., 2018). During meteorological conditions that are favorable for the formation of $\mathrm{O}_{3}$, local $\mathrm{O}_{3}$ formation can start from a still increasing initial $\mathrm{O}_{3}$ background. This is also exemplified by the trend in the number of days with $\mathrm{MDA}_{8} \mathrm{O}_{3}$ exceeding $35 \mathrm{ppb}$ for the 19902014 period, which is strongest for the two urban roadside sites in category E2 (supplementary material, Fig. S4). Consequently, a positive and statistically E2 (Fig. 10 and supplementary material Fig. S1).

At other urban, suburban and traffic related sites (categories D and E1) the number of days with MDA8 $\mathrm{O}_{3}$ exceeding $35 \mathrm{ppb}$ is also increasing and the trend of SOMO35 tends to be positive, although the trend estimates are not statistically significant. At rural sites (category C) the SOMO35 trends tend to be negative. Increase in SOMO35 at urban sites from lower values and decrease in SOMO35 in rural sites from higher values indicate that differences between rural and urban have become smaller during the studied period, which reflects trends in both the mean (Boleti et al., 2018) and peak concentrations. Exceptions are found at the sites of categories A and B, where an inflection point in SOMO35 is observed in the beginning of the 2000s. A linear trend is not suitable for characterizing this type of behavior and was therefore not estimated for these sites.

The calculated trends of the 90th percentile of meteo-adjusted daily maxi420 mum $\mathrm{O}_{3}$ can be compared to the trends found earlier by Ordóñez et al. (2005). 

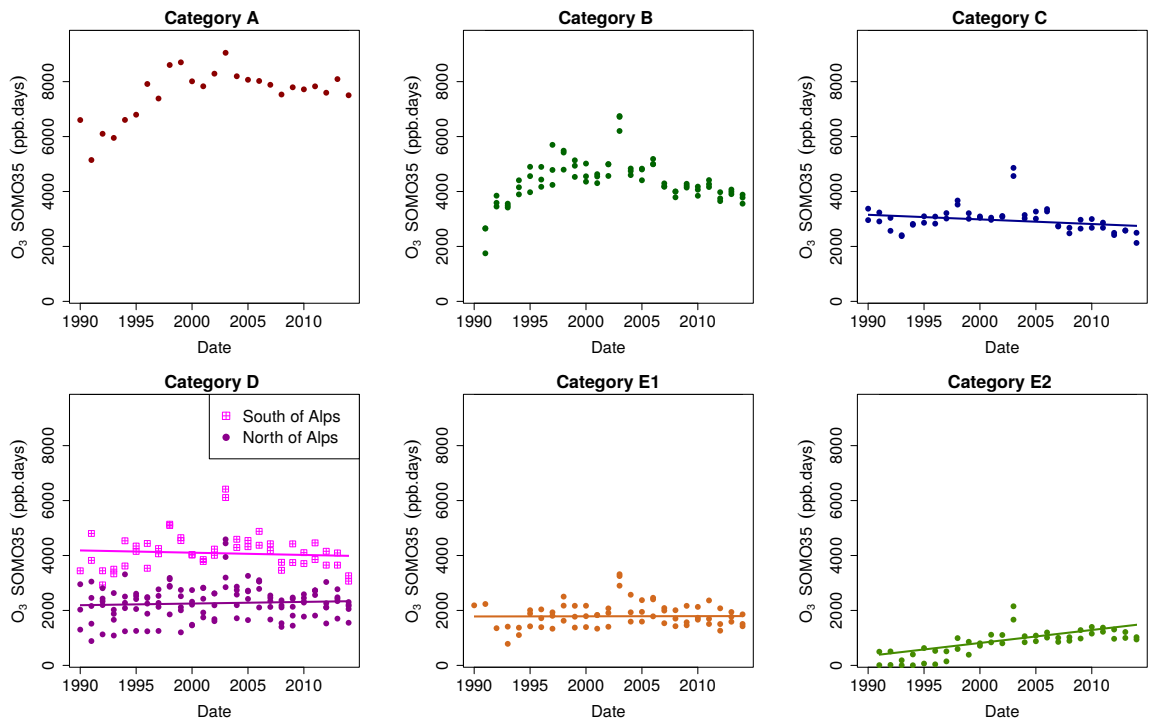

Figure 10: Same as in Fig. 9 for SOMO35. Note that meteo-adjustment was not applied for SOMO35. A linear trend is not shown for categories A and B as there is an inflection point during the studied time period.

For most of the sites covered by both studies, the calculated trends agree well although different data analytical approaches have been applied to observations during different time periods. For instance, downward trends were in both studies found in Zürich (ZUE) and Dübendorf (DUE) and an upward trend in LAU. However, for the rural traffic sites HAE and Sion (SIO), an upward trend was observed by Ordóñez et al. (2005) and downward trends were found in our study. The different trends in the two time periods (1992-2002 and 1990-2014) are due to an inflection point that is observed for the sites close to traffic, with a slight increase in the 1990s and decrease after mid-2000s. When the meteoadjustment approach used in this study is applied to the 1992-2002 time period as covered by Ordóñez et al. (2005) very similar and also not statistically significant trends have been obtained (supplementary material). Consequently, the significant trends of peak $\mathrm{O}_{3}$ described here for the 1990-2014 period benefit from the availability of a sufficiently long time series.

The importance of long time series of observations and the effect of special 
meteorological events in the trend estimation can also be seen by comparison of the results of this study with the EEA (2009) report. In EEA (2009), the trend of MTDM at rural Swiss sites was determined for the 1995-2005 period directly from the measurements and also from outputs of the regional EMEP Unified Chemical Transport Model. The MTDM trend as derived from the EMEP model was $-1.25 \mathrm{ppb} /$ year, the average trend calculated from the observations was almost zero (-0.01 ppb/year). When the methodology used in this study is applied to data from the same time period as used in EEA (2009), significant trends of meteo-adjusted MTDM were between -0.85 and $-0.5 \mathrm{ppb} /$ year for most rural and suburban sites (categories B, C and D). In the latest trend assessment report by EMEP, the median trend of the SOMO35 for rural background sites across Europe during the time period 1990-2012 has been determined to be 11 ppb.days/year with a $95 \%$ confidence interval $[-21,-2.4]$ ppb/year (EMEP 2016). The SOMO35 trends for similar site types (category C) in Switzerland found in this study is on average $-14.3[-34,11.8]$ ppb.days/year), which is not statistically significant but similar to the trends found across Europe. In the study by Fleming et al. (2018), significant negative SOMO35 trends for the period 2000-2014 were found for $20 \%$ of the non-urban sites in Europe, whereas for most of the urban sites the calculated trends were not significant. When SOMO35 trends are calculated for the same 2000-2014 period than in Fleming et al. (2018), mostly negative and significant trends were found in rural sites. For most suburban and urban sites, trends are also negative but non-significant (supplementary material, Fig. S9).

Analysis of peak $\mathrm{O}_{3}$ trends is naturally focusing on temporal changes of $\mathrm{O}_{3}$ selectively for conditions that are favourable for $\mathrm{O}_{3}$ formation. In contrast, mean $\mathrm{O}_{3}$ trends reflect changes in $\mathrm{O}_{3}$ as a consequence of all prevailing atmospheric conditions. However, comparison of the temporal changes in peak and mean $\mathrm{O}_{3}$ shows, that while peaks have been decreasing in rural, suburban and most urban sites in Switzerland after 1990, mean $\mathrm{O}_{3}$ mixing ratios started decreasing or leveling off only after mid-2000s (Boleti et al. 2018). At sites located very close to $\mathrm{NO}_{x}$ emission sources, both mean and peak $\mathrm{O}_{3}$ have been increasing 
since 1990 with signs of levelling off or decrease after mid-2000s. Inflection points for the mean $\mathrm{O}_{3}$ concentrations occurred in most cases later as for peak $\mathrm{O}_{3}$ (Boleti et al. 2018). Similar to our results, an inflection point for spring and summer season monthly averages has been detected in Mace Head between 2005-2008 while the annual averages peaked around 2007 (Derwent et al., 2018).

\section{Conclusions}

Peak $\mathrm{O}_{3}$ mixing ratios have been decreasing in most stations in Switzerland between 1990 and 2014. It was shown that meteo-adjusted MTDM and 4-MDA8 decreased in rural, suburban and most urban stations by around 0.5$1.2 \mathrm{ppb} /$ year and 0.4-0.6 ppb/year respectively. The behavior of the observed $\mathrm{O}_{3}$ long-term trends depends on the site type. At urban traffic sites all studied metrics increased between 1990 and 2014, due to reduced titration of $\mathrm{O}_{3}$. The trends of MTDM and 4-MDA8 are also positive at the remote site Jungfraujoch, here representing the increasing background $\mathrm{O}_{3}$ concentrations in Europe. The absence of significant trends of SOMO35 in suburban and urban areas indicates that health impacts from $\mathrm{O}_{3}$ as expressed by this metric remained largely unchanged for most of the Swiss population during the past 25 years.

The selection of the most important meteorological variables led to concise statistical models describing meteorological influence on maximum $\mathrm{O}_{3}$ concentrations at the studied sites. The most important meteorological variables for explaining the variability of $\mathrm{O}_{3}$ are temperature and humidity, followed by the wind speed, here expressed as east-west/north-south surface stress. The day of week has been found to be an important factor variable during the cold season only. Meteo-adjustment eliminated a large part of the meteorological driven variability in $\mathrm{O}_{3}$, allowing an earlier detection of statistically significant changes in tropospheric $\mathrm{O}_{3}$. This technique can particularly be useful when extreme meteorological conditions (e.g. heat waves) or temporal trends in meteorological variables might influence the trend estimation. Nevertheless, the availability 
tropospheric $\mathrm{O}_{3}$.

\section{Acknowledgements}

This study was supported by the Swiss Federal Office for the Environment (FOEN). We would like to thank Dr. Stephan Henne for extracting ERA-Interim meteorological variables.

\section{References}

, 2008. Health risks of ozone from long-range transboundary air pollution.

口 Technical Report. World Health Organization. URL: http://www . euro.who. int/__data/assets/pdf_file/0005/78647/E91843.pdf.

BAFU, 2016. NABEL Luftbelastung 2015. Technical Report UZ-1624-D.

BAFU, Swiss Federal Office of Environment, Empa, Swiss Federal Laboratories for Materials Science and Technology.

Barmpadimos, I., Hueglin, C., Keller, J., Henne, S., Prévôt, A.S.H., 2011. Influence of meteorology on PM10 trends and variability in Switzerland from 1991 to 2008. Atmospheric Chemistry and Physics 11, 1813-1835. doi: $10.5194 / \mathrm{acp}-11-1813-2011$.

Bärtsch-Ritter, N., Keller, J., Dommen, J., Prévôt, A.S.H., 2004. Effects of various meteorological conditions and spatial emission resolutions on the ozone concentration \& ROG/NOx limitation in the Milan area (I). Atmospheric Chemistry and Physics 3, 733-768. doi:10.5194/acp-4-423-2004.

Bloomer, B.J., Stehr, J.W., Piety, C.a., Salawitch, R.J., Dickerson, R.R., 2009. Observed relationships of ozone air pollution with temperature and emissions. Geophysical Research Letters 36, 1-5. doi:10.1029/2009GL037308.

Boleti, E., Hueglin, C., Takahama, S., 2018. Ozone time scale decomposition 520 and trend assessment from surface observations in switzerland. Atmospheric Environment doi:10.1016/j . atmosenv.2018.07.039. 
Brönnimann, S., Buchmann, B., Wanner, H., 2002. Trends in near-surface ozone concentrations in Switzerland: The 1990s. Atmospheric Environment 36, 2841-2852. doi $10.1016 / \mathrm{S} 1352-2310$ (02)00145-0.

Brönnimann, S., Neu, U., 1997. Weekend-weekday differences of near-surface ozone concentrations in Switzerland for different meteorological conditions.

घ Atmospheric Environment 31, 1127-1135. doi 10.1016/S1352-2310(96) 00311-1.

Carro-Calvo, L., Ordóñez, C., García-Herrera, R., Schnell, J.L., 2017. Spatial ${ }_{530}$ clustering and meteorological drivers of summer ozone in Europe n. Atmospheric Environment 167, 496-510. doi 10.1016/j . atmosenv.2017.08.050.

Carslaw, D.C., Beevers, S.D., Tate, J.E., 2007. Modelling and assessing trends in traffic-related emissions using a generalised additive modelling approach.

ㅁ Atmospheric Environment 41, 5289-5299. doi 10.1016/j.atmosenv.2007. $535 \quad 02.032$.

Chernick, M.R., 2008. Bootstrap Methods, A guide for practicioners and researchers.

Coates, J., Mar, K.A., Ojha, N., Butler, T.M., 2016. The influence of temperature on ozone production under varying NOx conditions - a modelling ${ }_{540}$. study. Atmospheric Chemistry and Physics 16, 11601-11615. doi 10.5194/ acp-16-11601-2016.

Colette, A., Granier, C., Hodnebrog, O., Jakobs, H., Maurizi, A., Nyiri, A., Bessagnet, B., D'Angiola, A., D'Isidoro, M., Gauss, M., Meleux, F., Memmesheimer, M., Mieville, A., Roüil, L., Russo, F., Solberg, S., Stordal, F., Tampieri, F., 2011. Air quality trends in Europe over the past decade: A first multi-model assessment. Atmospheric Chemistry and Physics 11, 1165711678. doi $10.5194 / \mathrm{acp}-11-11657-2011$

Cooper, O.R., Parrish, D.D., Ziemke, J., Balashov, N.V., Cupeiro, M., Galbally, I.E., Gilge, S., Horowitz, L., Jensen, N.R., Lamarque, J.F., Naik, V., Oltmans, 
S.J., Schwab, J., Shindell, D.T., Thompson, A.M., Thouret, V., Wang, Y., Zbinden, R.M., 2014. Global distribution and trends of tropospheric ozone: An observation-based review. Elementa: Science of the Anthropocene 2, 000029. doi $10.12952 /$ journal.elementa.000029.

Davies, L., Jakob, C., May, P., Kumar, V.V., Xie, S., 2013. Relationships between the large-scale atmosphere and the small-scale convective state for Darwin, Australia. Journal of Geophysical Research Atmospheres 118, 1153411545. doi $10.1002 /$ jgrd.50645.

Dentener, F., Keating, T., Akimoto, H., 2010. Hemispheric Transport of Air Pollution, Part A: Ozone and Particulate Matter. Technical Report 11.II.E.7. UNECE.

Derwent, R., Simmonds, P., Manning, A., Spain, T., 2007. Trends over a 20-year period from 1987 to 2007 in surface ozone at the atmospheric research station,

口 Mace Head, Ireland. Atmospheric Environment 41, 9091-9098. doi 10.1016/ j.atmosenv.2007.08.008.

Derwent, R., Stevenson, D.S., Collins, W.J., Johnson, C.E., 2004. Intercontinental transport and the origins of the ozone observed at surface sites in Europe.

n Atmospheric Environment 38, 1891-1901. doi 10.1016/j.atmosenv. 2004. 01.008 .

Derwent, R.G., Manning, A.J., Simmonds, P.G., Doherty, S.O., 2018. Longterm trends in ozone in baseline and European regionally-polluted air at Mace Head, Ireland over a 30-year period. Atmospheric Environment 179, 279-287. doi:10.1016/j.atmosenv.2018.02.024

EEA, 2009. Assessment of ground-level ozone in EEA member countries, with a focus on long-term trends. Technical Report 7. European Environmental 575 Agency.

EEA, 2015. Air quality in Europe-2015 report. Technical Report 5. Euro- 
1] pean Environmental Agency. URL: http://www.actu-environnement.com/ media/pdf/news-25756-rapport-air-aee.pdf doi:10.2800/62459.

EEA, 2017. Air quality in Europe 2017 report. Technical Report 13. European

Environmental Agency. doi $10.2800 / 850018$.

EEA, 2018. Air quality in Europe 2017 report. Technical Report 13. European Environmental Agency. doi:10.2800/850018.

EMEP, 2016. Air pollution trends in the EMEP region between 1990 and 2012. Technical Report 1. EMEP Task Force on Measurements and Modelling (TFMM),Chemical Co-ordinating Centre (CCC), Meteorological Synthesizing Centre-East (MSC-E), Meteorological Synthesizing Centre-West (MSC-W). URL: https://www.nilu.no/projects/ccc/tfmm/.

European Parliament and Council of the European Union, 2008. Directive 2008/50/EC of the European Parliament and of the Council of 21 May 2008 on ambient air quality and cleaner air for Europe. Technical Report. European Parliament and Council of the European

\Union. URL: http://eur-lex.europa.eu/LexUriServ/LexUriServ.do? uri=0J :L:2008:152:0001:0044:EN:PDF

Finlayson-Pitts, B., Pitts, J., 2000. Chemistry of the Upper and Lower Atmosphere: Theory, Experiments, and Applications. Academic Press.

Fleming, Z.L., Doherty, R.M., Schneidemesser, E.V., Malley, C.S., Cooper, O.R., Pinto, J.P., Colette, A., Xu, X., Simpson, D., Schultz, M.G., Lefohn, A.S., Hamad, S., Moolla, R., Solberg, S., 2018. Tropospheric Ozone Assessment Report: Present-day ozone distribution and trends relevant to 600 human health. Elementa: Science of the Anthropocene 6. doi https: //doi.org/10.1525/elementa.273.

Grange, S.K., Lewis, A.C., Moller, S.J., Carslaw, D.C., 2017. Lower vehicular primary emissions of NO2 in Europe than assumed in policy projections. Nature Geoscience doi:10.1038/s41561-017-0009-0. 
Grice, S., Stedman, J., Kent, A., Hobson, M., Norris, J., Abbott, J., Cooke, S., 2009. Recent trends and projections of primary NO2 emissions in Europe.

1. Atmospheric Environment 43, 2154-2167. doi:10.1016/j.atmosenv. 2009. 01.019 .

Guerreiro, C.B., Foltescu, V., de Leeuw, F., 2014. Air quality status and 610 trends in Europe. Atmospheric Environment 98, 376-384. doi $10.1016 / \mathrm{j}$. atmosenv.2014.09.017.

Hall, P., 1996. The Bootstrap and Edgeworth Expansion.. vol1 ume 45. URL: http://www.jstor.org/stable/10.2307/2988556?origin= crossref, doi:10.1007/978-1-4612-4384-7, arXiv:arXiv:1011.1669v3.

${ }_{615}$ Hastie, T., Tibshirani, R., 1990. Generalized Additive Models. Statistical Science 1, 297-310. doi:10.1214/ss/1177013604.

Henschel, S., Le Tertre, A., Atkinson, R.W., Querol, X., Pandol, M., Zeka, A., Haluza, D., Analitis, A., Katsouyanni, K., Bouland, C., Pascal, M., Medina, S., Goodman, P.G., 2015. Trends of nitrogen oxides in ambient air in nine European cities between 1999 and 2010. Atmospheric Environment 117, 234241. doi $10.1016 / j$. atmosenv . 2015.07.013.

Hess, P.G., Zbinden, R., 2013. Stratospheric impact on tropospheric ozone variability and trends: 1990-2009. Atmospheric Chemistry and Physics 13, 649-674. doi:10.5194/acp-13-649-2013

625 Jackson, L.S., Carslaw, N., Carslaw, D.C., Emmerson, K.M., 2009. Modelling trends in $\mathrm{OH}$ radical concentrations using generalized additive mod-

q els. Atmospheric Chemistry and Physics 9, 2021-2033. doi 10.5194/ acp-9-2021-2009.

Marr, L.C., Harley, R.A., 2002. Spectral analysis of weekday-weekend differ${ }_{630}$ ences in ambient ozone, nitrogen oxide, and non-methane hydrocarbon time 口 series in california. Atmospheric Environment 36, 2327-2335. doi 10.1016/ S1352-2310(02) 00188-7. 
Monks, P.S., 2000. A review of the observations and origins of the spring S1352-2310(00) 00129-1.

Ordóñez, C., Mathis, H., Furger, M., Henne, S., Hueglin, C., Staehelin, J., Prévôt, A.S.H., 2005. Changes of daily surface ozone maxima in Switzerland in all seasons from 1992 to 2002 and discussion of summer 2003. Atmospheric Chemistry and Physics 5, 1187-1203. doi 10.5194/acp-5-1187-2005

${ }_{640}$ Otero, N., Sillmann, J., Schnell, J.L., Rust, H.W., Butler, T., 2016. Synoptic and meteorological drivers of extreme ozone concentrations over Europe.

口 Environmental Research Letters 11, 24005. doi 10.1088/1748-9326/11/2/ 024005 .

Pearce, J.L., Beringer, J., Nicholls, N., Hyndman, R.J., Tapper, N.J., 2011. Quantifying the influence of local meteorology on air quality using generalized

q additive models. Atmospheric Environment 45, 1328-1336. doi $10.1016 / j$. atmosenv.2010.11.051.

Prévôt, A.S.H., Staehelin, J., Kok, L., Schillawski, D., Neininger, B., Staffelbach, T., Neftel, A., Wernli, H., Dommen, J., 1997. The Milan photooxidant 650 \ plume. Journal of Geophysical Research 102, 23375-23388. doi 10.1029/ 97JD01562.

Querol, X., Alastuey, A., Reche, C., Orio, A., Pallares, M., Reina, F., Dieguez, J.J., Mantilla, E., Escudero, M., Alonso, L., Gangoiti, G., Millán, M., 2016. On the origin of the highest ozone episodes in Spain. Science of the Total Environment 572, 379-389. doi:10.1016/j.scitotenv.2016.07.193.

R Development Core Team, 2017. R: A Language and Environment for Statistical Computing. R Foundation for Statistical Computing. Vienna, Austria. URL: http://www.R-project.org. ISBN 3-900051-07-0.

Schnell, J.L., Holmes, C.D., Jangam, A., Prather, M.J., 2014. Skill in forecasting extreme ozone pollution episodes with a global atmospheric chem- 
n istry model. Atmospheric Chemistry and Physics , 7721-7739doi 10.5194/ acp-14-7721-2014

Seinfeld, J., Pandis, S., 2016. Atmospheric Chemistry and Physics: From Air Pollution to Climate Change. John Wiley, Hoboken, NJ.

Sen, P., 1968. Estimates of the regression coefficient based on Kendalls tau.

q Journal of American Statistical Association 63, 1379-1389. doi 10.1080/ 01621459.1968 .10480934

Sillman, S., Logan, J.A., Wofsy, S.C., 1990. The sensitivity of ozone to nitrogen oxides and hydrocarbons in regional ozone episodes. Journal of Geophysical Research: Atmospheres 95, 1837-1851. doi 10.1029/JD095iD02p01837.

Sillman, S., Samson, P.J., 1995. Impact of temperature on oxidant photochemistry in urban, polluted rural and remote environments. Journal of Geophysical Research-Atmospheres 100, 11497-11508. doi 10.1029/94JD02146.

Staehelin, J., Thudium, J., Buehler, R., Volz-Thomas, A., Graber, W., 1994. Trends in surface ozone concentrations at Arosa (Switzerland). Atmospheric Environment 28, 75-87. doi 10.1016/1352-2310(94)90024-8.

Theil, H., 1950. A rank-invariant method of linear and polynomial regression analysis, part 3, in: Proceedings of Koninalijke Nederlandse Akademie van Weinenschatpen A, pp. 1397-1412. doi:10.1007/978-94-011-2546-8_20.

Thompson, M., Reynolds, J., Cox, L.H., Guttorp, P., Sampson, P.D., 2001. A review of statistical methods for the meteorological adjustment of tropospheric

口 Ozone. Atmospheric Environment 35, 617-630. doi 10.1016/S1352-2310(00) 00261-2.

Vingarzan, R., 2004. A review of surface ozone background levels and trends. 685 \. Atmospheric Environment 38, 3431-3442. doi:10.1016/j.atmosenv.2004. 03.030 . 
Vogel, B., Riemer, N., Vogel, H., Fiedler, F., 1999. Findings on NOy as an indicator for ozone sensitivity based on different numerical simulations. Journal of Geophysical Research 104, 3605-3620. doi 10.1029/1998JD100075

Weusthoff, T., 2011. Weather Type Classification at MeteoSwiss - Introduction of new automatic classification schemes. Technical Report 235. MeteoSwiss.

Wood, S., 2006. Generalized Additive Models: An Introduction with R. Chapman \& Hall/CRC press.

World Health Organization, 2006. WHO Air quality guidelines for particulate matter, ozone, nitrogen dioxide and sulfur dioxide: global update 2005: summary of risk assessment. Technical Report. World Health Organization. URL: http://apps .who.int/iris/bitstream/10665/69477/1/WHO_ SDE_PHE_OEH_06.02_eng.pdf, doi:10.1016/0004-6981(88)90109-6.

Yan, Y., Pozzer, A., Ojha, N., Lin, J., Lelieveld, J., 2018. Analysis of European ozone trends in the period 1995-2014. Atmospheric Chemistry and Physics doi: $10.5194 /$ acp-18-5589-2018 